\title{
New acetate-intercalated CoNiFe, ZnNiFe and CoZnFe layered double hydroxides: Synthesis by forced hydrolysis in polyol medium and characterization
}

\author{
Nawal Drici Setti ${ }^{*} a, b, Z$ Zoubir Derriche ${ }^{b}$, Noureddine Jouini ${ }^{a}$
}

'Laboratoire des sciences des procédés et des matériaux, CNRS-LSPM, UPR 3407 université paris 13, Sorbonne Paris Cité, 99 Avenue Jean- Baptiste Clément, 93430 Villetaneuse, France.

$$
\text { jouini@univ-paris13.fr }
$$

${ }^{\mathbf{b}}$ Laboratoire de physico-chimie des matériaux, catalyse et environnement LPCMCE, Université des Sciences et de Technologie « Mohamed Boudiaf » d'Oran, USTO-MB, M'Nouar 1505, Oran 31000, Algérie

drici_nawel@yahoo.fr (*Corresponding author), derriche_zoubir@yahoo.com

\section{ABSTRACT}

New layered double hydroxides (LDHs) CoNiFe, ZnNiFe and CoZnFe with $\mathrm{M}^{\prime \prime} / \mathrm{M}^{\prime \prime \prime}$ molar ratio of 3, with acetate ions in the interlayer region have been prepared by forced hydrolysis in polyol medium.

The physico-chemical properties of all products were characterized by the methods of powder X-ray Diffraction, Infrared Spectroscopy, UV-Spectroscopy, Elemental analysis, Thermal analysis, Transmission Electron Microscopy and Scanning Electron Microscopy.

It was found that all compounds present the typical features of hydrotalcite-like structure and exhibit a turbostratic character.

The insertion of acetate anions into LDHs was confirmed and the interlayer spacing values were respectively $12.47,13.64$ and $14.69 \AA$ for CoNiFe, ZnNiFe and CoZnFe.

We notice a difference between the interlayer spacing for all synthesized phases with and without zinc. This can be explained by a structural modification on the level of the layers and/ or different arrangement from the inserted species (anions + water) in the interlayer space for zinc materials.

${ }^{57} \mathrm{Fe}$ Mössbauer spectrometry allows concluding the presence of $\mathrm{Fe}^{3+}$ cations which occupy octahedral sites and confirming the absence of $\mathrm{Fe}^{2+}$ in the as-prepared compounds.

\section{Keywords}

Layered Double Hydroxide; Polyol; Forced Hydrolysis; Anionic Exchange; Chemical synthesis; X-ray diffraction; Mössbauer spectrometry

\section{Academic Discipline And Sub-Disciplines}

Solid State Chemistry - Layered Materials

\section{SUBJECT CLASSIFICATION}

Chemistry Subject Classification

\section{TYPE (METHOD/APPROACH)}

Experimental study- synthesis method

\section{Council for Innovative Research}

\author{
Peer Review Research Publishing System
}

Journal: Journal of Advances in Chemistry

Vol. 10, No. 9

editorjaconline@gmail.com

www.cirjac.com 


\section{INTRODUCTION}

Hydrotalcite-like compounds, also called anionic clays or layered double hydroxides (LDHs) are very attractive materials for a broad range of applications [1, 2]. They can be presented by the general formula $\left[\mathrm{M}^{\prime \prime}{ }_{1-x} \mathrm{M}^{\prime \prime \prime}{ }_{x}(\mathrm{OH})_{2}\right]^{+\times / n}\left(A^{-n}\right) \times / n \cdot m H_{2} \mathrm{O}$. The positive layer charge is created by substituting a divalent cation with a trivalent one in the octahedral hydroxide layer, with anions $\left(A^{-n}\right)$ and water in the interlayer space [3].

LDHs are elaborated by several synthesis methods: coprecipitation at fixed $\mathrm{pH}$ and exchange reactions [4], reconstruction [5], mechanochemical process [6] and reverse microemulsion method [7]. However the coprecipitation is the most commonly used method with carbonate as the intercalated anion in the most cases. Despite its widespread use, this method presents two main disadvantages. First, it needs a precise control of several parameters mainly the $\mathrm{pH}$. Second, the carbonate anion has a great affinity toward the inorganic layer charged positively. This limits exchange reactions and thus the obtention of LDHs with desired intercalated anions.

Recently an alternative synthesis method has been proposed. It takes advantages from the various properties of polyols. Indeed it has been shown that two main reactions can be easily conducted in such medium: namely reduction and forced hydrolysis along with inorganic polymerization [8] [9]. The competition between these two reactions can be easily controled by the hydrolysis ratio defined as $\mathrm{h}=\mathrm{nH}_{2} \mathrm{O} / \mathrm{nM}$. This led to the synthesis of various inorganic materials: metal, oxides, layered hydroxide salts (LHS) and more recently LDH compounds: LDH-Ni-Al [10] and LDH-Ni-Fe [11] with acetate as the intercalated anion.

In this paper, we want to put this novel route, efficiency for synthesis of a series of layered double hydroxides containing three transition metals CoNiFe, $\mathrm{ZnCoFe}$, and $\mathrm{ZnNiFe}$ with acetate anions intercalated in the interlayer space. The obtained LDH are characterised by several complementary analyses (X--ray diffraction, TEM, DTA-TGA, IR, UV and Mossbauer spectroscopy). Such LDHs based on transition metals are of great interest as precursors for metal-spinel oxides composites with potential magnetic and catalytic properties [12].

\section{EXPERIMENTAL METHODS}

\section{1. Materials}

For all preparative procedures, $\mathrm{Zn}\left(\mathrm{CH}_{3} \mathrm{COO}\right)_{2} .4 \mathrm{H}_{2} \mathrm{O}, \mathrm{Ni}\left(\mathrm{CH}_{3} \mathrm{COO}\right)_{2} .4 \mathrm{H}_{2} \mathrm{O}, \mathrm{Fe}\left(\mathrm{CH}_{3} \mathrm{COO}\right)_{2}, \mathrm{Co}\left(\mathrm{CH}_{3} \mathrm{COO}\right)_{2} .4 \mathrm{H}_{2} \mathrm{O}, \mathrm{NaOH}$ and diethylène glycol (DEG) were purchased from Acros and used without any further purification.

\section{2. Synthesis of LDHs Samples}

The samples were synthesized with a molar ratio $(\mathrm{M} / \mathrm{Fe})$ of 3 by forced hydrolysis in polyol medium according to the method described by Poul et al. for elaboration of layered hydroxysalts [8]. It consists in the hydrolysis at $130^{\circ} \mathrm{C}$ of mixture of acetate salts dissolved in DEG with a total molar concentration of $0.1 \mathrm{~mole} / \mathrm{L}$.

The precipitation of the corresponding LDHs occurred when the hydrolysis and alkalinity ratios $h$ and $b$ were fixed at 100 and 2 respectively, where $\mathrm{h}=\mathrm{nH}_{2} \mathrm{O} / \mathrm{n}(\mathrm{M}+\mathrm{Fe})$ and $\mathrm{b}=\mathrm{nNaOH} / \mathrm{n}(\mathrm{M}+\mathrm{Fe})$.

The suspensions were kept under continuous stirring for 6 hours. After separation by centrifugation, the solids CoNiFeAc, $\mathrm{ZnNiFe}$ and $\mathrm{ZnCoFe}-\mathrm{Ac}$ were dried under air at $60^{\circ} \mathrm{C}$.

\subsection{Characterization}

Powder X-ray diffraction (PXRD) patterns were obtained at room temperature using a Inel diffractometer with Co-Ka1 radiation $\left(\lambda_{\text {Coa } 1}=1.7889 \AA\right)$. The crystallite size was calculated using the Scherrer equation. Scanning electron microscopy study was performed using LEICA STEREOSCAN 440 instrument. Electron microscopy and diffraction studies were performed on a JEOL-100 CX II microscope. Infrared spectra were recorded by transmission on PERKIN ELMER 1750 spectrometer on pressed $\mathrm{KBr}$ pellets with $4 \mathrm{~cm}^{-1}$ resolution between 400 and $4000 \mathrm{~cm}^{-1}$. Elemental analysis (metal, carbon and hydrogen) was performed by ICP method at the centre national de la recherche scientifique, service central d'analyse à SOLAIZE (France). Differential thermal and thermogravimetric analyses (DTA and TGA) were carried out on a Setaram TG 92-12 thermal analyzer with heating rate $1^{\circ} \mathrm{C} / \mathrm{mn}$ under argon, in alumina crucible. UV-Visible spectra were recorded between 200 and $2500 \mathrm{~nm}$, with Cary 5/Varian spectrometer. Polytetrafluoroethylene (PTFE) was used as a reference. The ${ }^{57} \mathrm{Fe}$ Mössbauer spectra were recorded in a transmission geometry using a ${ }^{57} \mathrm{Co} / \mathrm{Rh} \gamma$-ray source. They were analyzed by a least-squares fitting method to lorentzian function. The isomer shifts $(\delta)$ were referred to that of $\alpha$-Fe at 300 $\mathrm{K}$. The sample (area: $3 \mathrm{~cm}^{2}$ ) has been prepared by dispersion of the compound $(40 \mathrm{mg})$ in a specific resin.

\section{RESULTS AND DISCUSSION}

\subsection{X-ray diffraction study}

The X-ray diffraction patterns of all the synthesized compounds (Fig. 1) have typical features of turbostratic lamellar compounds [13]. Indeed, three (00/) sharp and symmetric peaks at low diffraction angles, and two broad, less intense and asymmetric peaks can be clearly identified. The patterns were indexed in a hexagonal lattice with rhombohedral symmetry (R-3m), commonly used as a description of the layered double hydroxide structure [14]. The value of the crystallographic parameter $a$ which is the average metal-metal distance in the brucite-like layers of the LDH compounds, has been 
calculated from $d_{110}\left(a=2 d_{110}\right)$, whilst, the value of parameter $c$ which is related to the thickness of the brucite-like layers, the nature of the interlayer anion and water content, has been also determined.

The insertion of acetate anions into LDHs was confirmed and the interlayer spacing values were respectively $12.47,13.64$ and 14. $69 \AA$ A for CoNiFe, ZnNiFe and CoZnFe (Table 1).

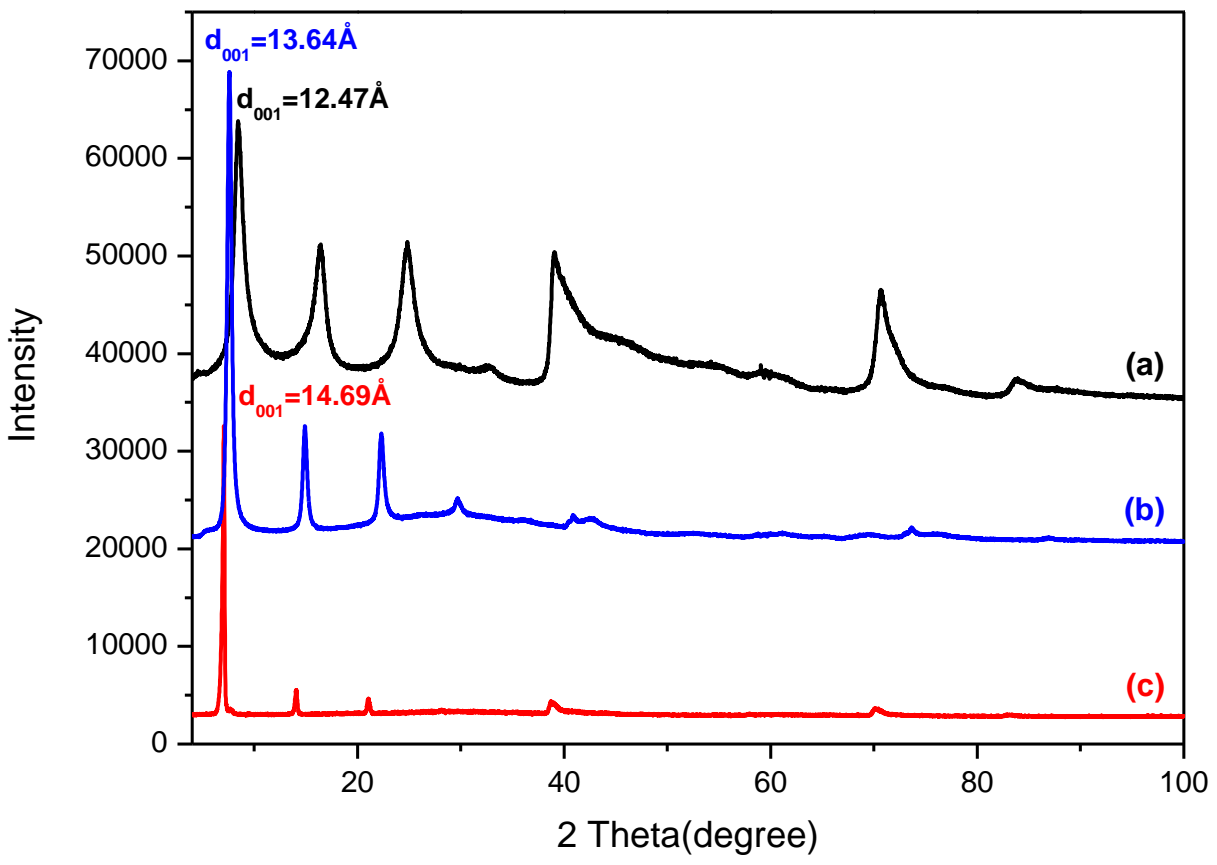

Figure 1: XRD patterns of LDHs, (a) CoNiFe-Ac, (b) ZnNiFe-Ac, (c) ZnCoFe-Ac.

Table 1: Lattice parameters (from XRD data) of LDH samples

\begin{tabular}{|c|c|c|c|c|}
\hline Compound & $\begin{array}{c}a=2 d_{110} \\
(\AA)\end{array}$ & $d_{001}(A)$ & $\begin{array}{c}\text { Correlation length according to c } \\
\text { axis }(\AA)\end{array}$ & $\begin{array}{l}\text { Number of monolayers } \\
\text { /crystallite }\end{array}$ \\
\hline CoNiFe-Ac & 3.08 & 12.47 & 60 & 5 \\
\hline ZnNiFe-Ac & 3.06 & 13.64 & 228 & 16 \\
\hline ZnCoFe-Ac & 3.10 & 14.69 & 490 & 33 \\
\hline
\end{tabular}

We notice a difference between the interlayer spacing for all synthesized phases. This can be explained by a structural modification on the level of the layers and/ or different arrangement for the inserted species (anions + water) in the interlayer space for zinc materials. The correlation length along $c$ deduced from the XRD analysis (Table 1) reveals a better cristallinity for $\mathrm{ZnCoFe}-\mathrm{Ac}$ in comparison with CoNiFe-Ac and $\mathrm{ZnNiFe}-\mathrm{Ac}$ compounds. In this case, it corresponds to the stacking of approximately 33 layers by crystallite.

\section{2. Morphology}

SEM images of all synthesized materials show the low level of cristallinity and confirm the turbostratic character of these compounds. Fig. 2(a) and (b) depict the SEM images of CoNiFe-Ac and ZnNiFe-Ac systems respectively, it is clearly seen that these particles are precipitated as small, pseudo-spherical aggregates of platelets; they are also very similar to the morphology of other LDHs [15].

The particles of ZnCoFe-Ac (Fig. 2(c)) sample are formed by the aggregation of small platy crystallites without any definite shape. They appear to be denser compared to those of the CoNiFe-Ac and ZnNiFe-Ac. 


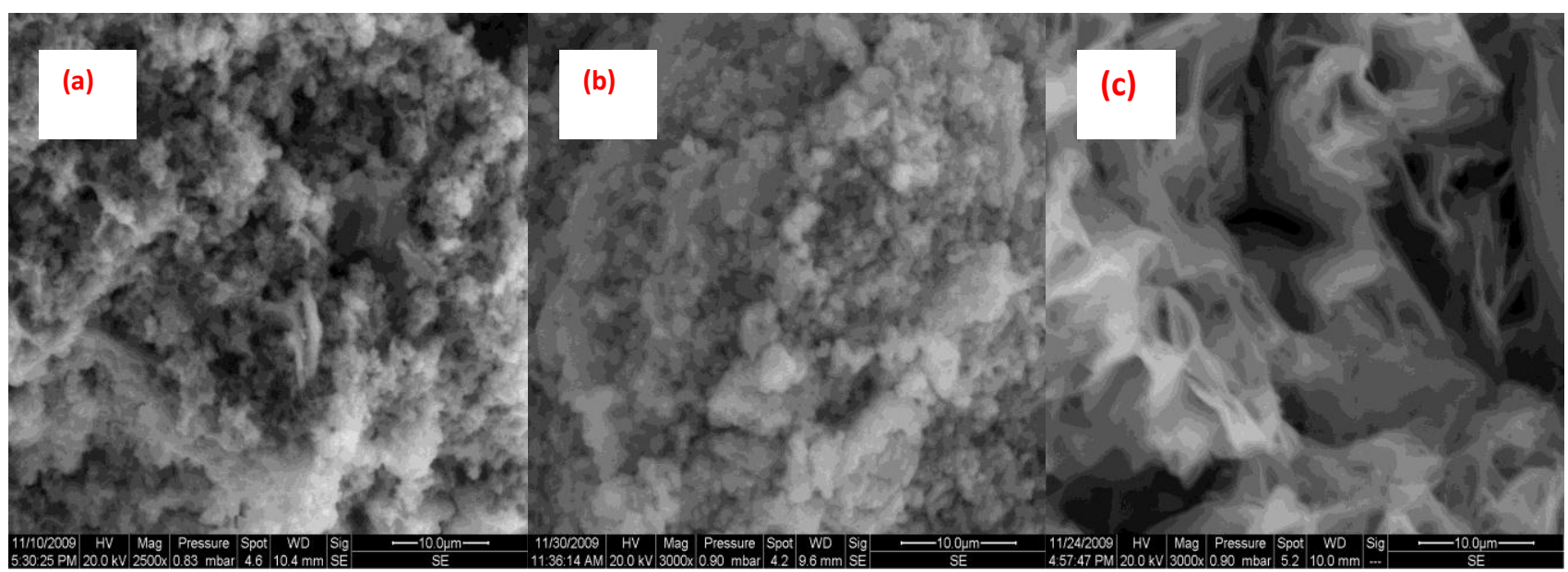

Figure 2: SEM images of LDHs, (a) CoNiFe-Ac, (b) ZnNiFe-Ac, (c) ZnCoFe-Ac.

For TEM images, the particles of all compounds appear as aggregates of thin crumpled sheets with irregular size and shape (Fig. 3). This aggregation is similar to that described by Taibi et al. for NiFe-Ac LDH [11]. Electron diffraction pattern of these samples confirm the hexagonal symmetry of the brucite structure, to which all the hydrotalcite-like materials belong. The preferential orientation of the crystallites along the $(001)$ heaxogal plane is clearly established for CoNiFe sample (Fig. 4).

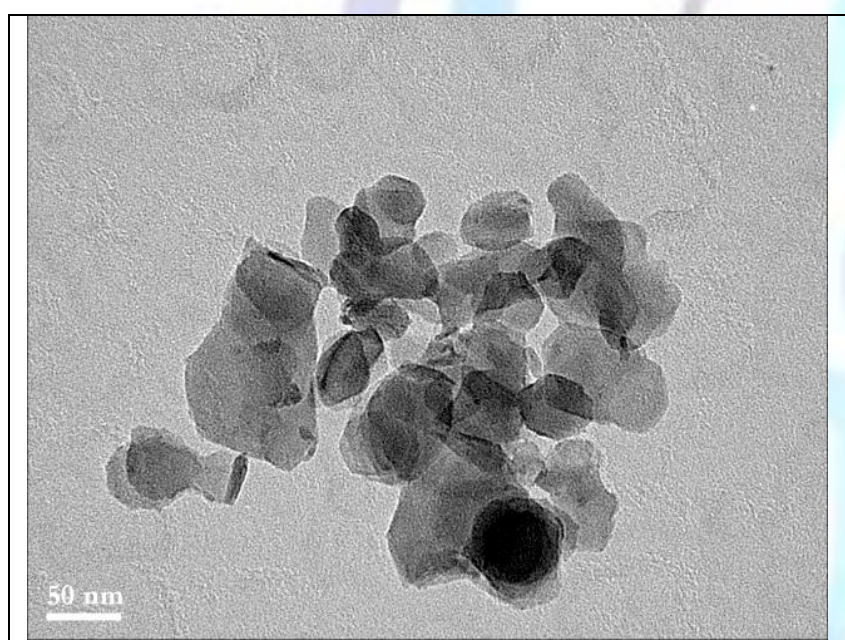

Figure 3:TEM images of LDHs CoNiFe-Ac.

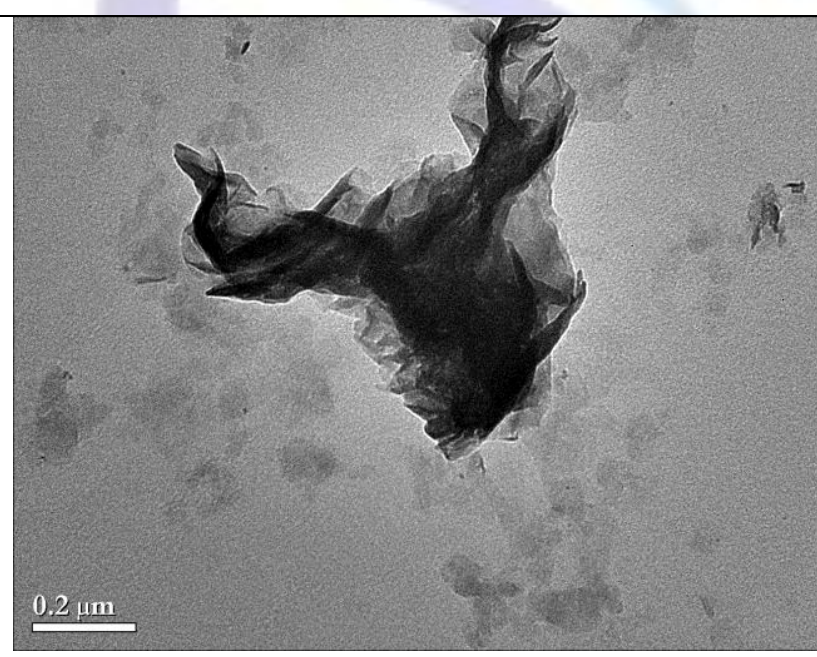

Figure 3: TEM images of LDHs ZnCoFe-Ac.

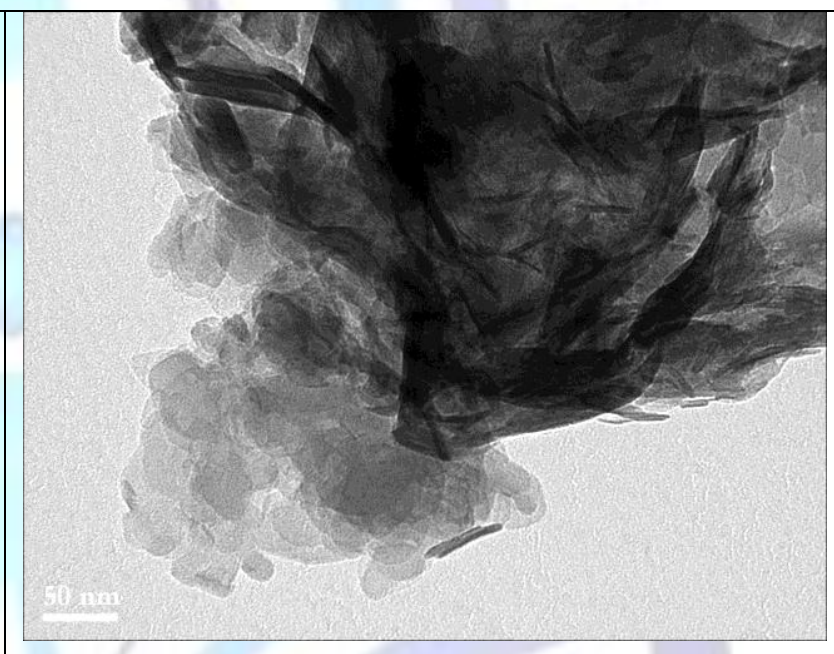

Figure 3: TEM images of LDHs ZnNiFe-Ac. 


\section{3. Infrared Spectroscopy}

IR spectra for all samples are shown in Figure 5. The broad absorption bands at high frequency $\left(3600-3400 \mathrm{~cm}^{-1}\right)$ indicate the presence of $\mathrm{OH}$ groups and water molecules in the brucite-like layer. The absorption band around $1640 \mathrm{~cm}^{-1}$ for $\mathrm{CoNiFe}-\mathrm{Ac}$ and $\mathrm{ZnCoFe}-\mathrm{Ac}$ is assigned to $\delta \mathrm{H} 2 \mathrm{O}$ vibration of the water molecules [16, 17]. In the case of $\mathrm{ZnNiFe}-\mathrm{Ac}$, this band is obscured by the strong band due to the $v_{a s}\left(-\mathrm{COO}^{-}\right)$of the acetate anion [18].

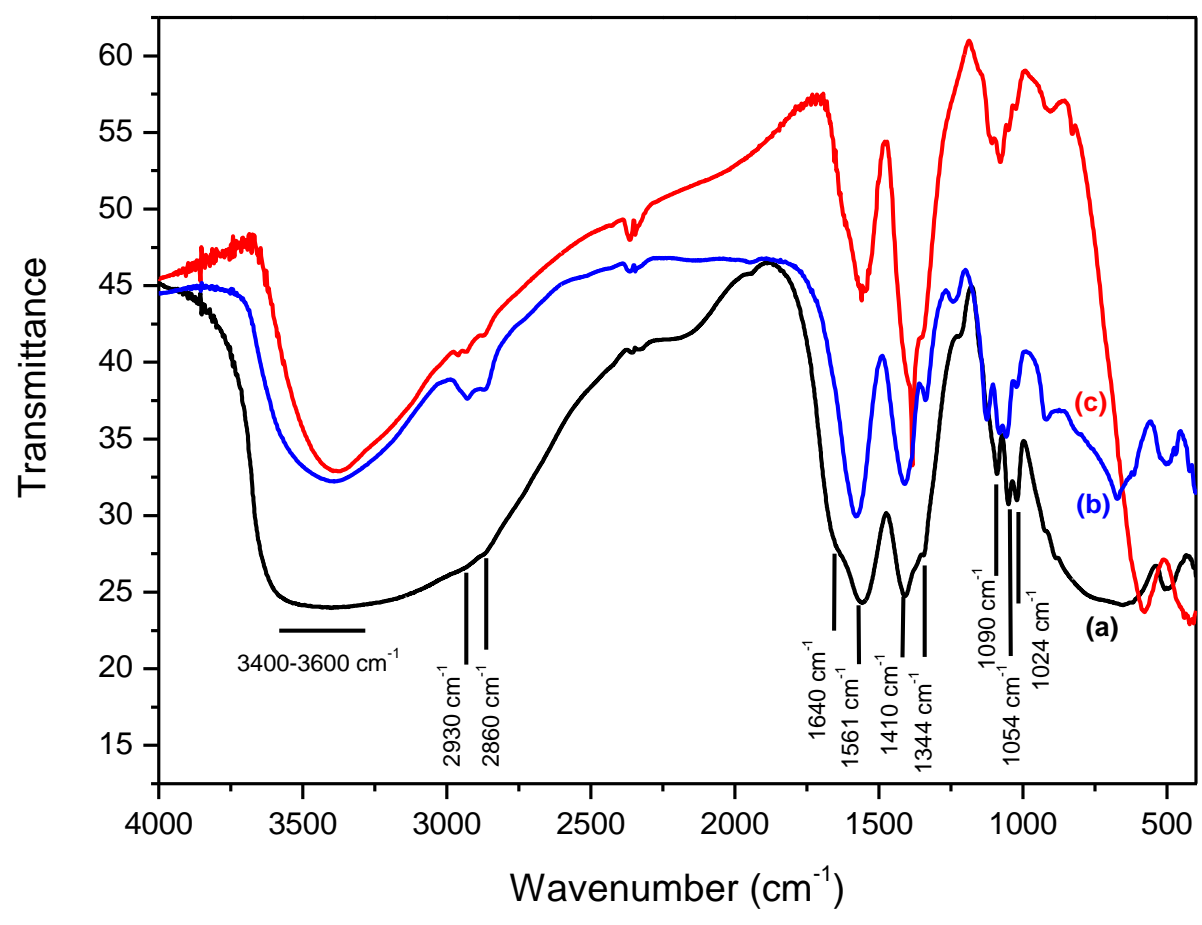

Figure 5: FT-IR spectra LDHs (a) CoNiFe-Ac, (b) ZnNiFe-Ac, (c) ZnCoFe-Ac.

The presence of acetate anions in the interlayer of all compounds is attested by the presence of two large and intense bands in 1600-1000 $\mathrm{cm}^{-1}$ domain, which are assigned to $v_{\mathrm{as}}(-\mathrm{COO})$ and $\mathrm{v}_{\mathrm{s}}\left(-\mathrm{COO}^{-}\right)$respectively. $\mathrm{v}_{\mathrm{as}}\left(-\mathrm{COO}^{-}\right)=1561 \mathrm{~cm}^{-1}$ for CoNiFe-Ac and ZnCoFe-Ac and $1579 \mathrm{~cm}^{-1}$ for ZnNiFe-Ac. $v_{\mathrm{s}}(-\mathrm{COO})=1410 \mathrm{~cm}^{-1}$ for CoNiFe-Ac and ZnNiFe-Ac and $1386 \mathrm{~cm}^{-1}$ for ZnCoFe-Ac [19].

According to Nakamoto rules [20], the value of $\Delta v=\left(v_{a s}-v_{s}\right)$, where $175 \leq \Delta v \leq 151 \mathrm{~cm}^{-1}$ confirms that acetate anions are intercalated as free species in between the layers.

The absorption bands around $1344 \mathrm{~cm}^{-1}$ are attributed to $\mathrm{CH}_{3}$ vibrations [19]. The existence of a low-intensity bands between 1300 and $1000 \mathrm{~cm}^{-1}$ indicate the presence of DEG molecules as adsorbed species [11]. Bands at lower wavenumber $\left(\mathrm{v}<800 \mathrm{~cm}^{-1}\right)$ are due to vibrations implying $\mathrm{M}-\mathrm{O}, \mathrm{M}-\mathrm{O}-\mathrm{M}$ and $\mathrm{O}-\mathrm{M}-\mathrm{O}$ bonds in the layer $[17,21]$.

The band close to $1360 \mathrm{~cm}^{-1}$ is absent in all spectra, confirming the intercalation of all compounds with acetate anions without any trace impurity of carbonate anions.

\section{4. Thermal analysis}

The TG/DTA analysis for all samples is shown in Figure 6. Three weight losses are observed for each sample. The first weight loss corresponds to the removal of adsorbed and interlayer water molecules, the second weight loss is due to dehydroxylation of the brucite-like layers, while the third one is due to the removal of interlayer anions [22].

For all compounds, three endothermic effects can be distinguished in the DTA curve. The first endothermic peak due to the loss of surface and interlayer water was observed at $116^{\circ} \mathrm{C}$ with loss of mass of $6.3 \%$ for $\mathrm{CoNiFe}-\mathrm{Ac}$, at $83^{\circ} \mathrm{C}(7.3 \%)$ for $\mathrm{ZnNiFe}-\mathrm{Ac}$ and at 82 and $127^{\circ} \mathrm{C}(9.4 \%)$ for ZnCoFe-Ac.

The second effect, attributed to the dehydroxylation process, was seen at $187^{\circ} \mathrm{C}(10.3 \%)$ for $\mathrm{CoNiFe}-\mathrm{Ac}$, at 132 and $229^{\circ} \mathrm{C}(13 \%)$ for $\mathrm{ZnNiFe}-\mathrm{Ac}$ and at $200^{\circ} \mathrm{C}(10.3 \%)$ for $\mathrm{ZnCoFe}-\mathrm{Ac}$.

The third and the last endothermic effects which are likely related to the decomposition of acetate anions, appeared at $290^{\circ} \mathrm{C}$ and $430^{\circ} \mathrm{C}(29.3 \%)$ for CoNiFe-Ac, at 288 and $414^{\circ} \mathrm{C}(31 \%)$ for $\mathrm{ZnNiFe}-\mathrm{Ac}$ and at $292^{\circ} \mathrm{C}(21.4 \%)$ for $\mathrm{ZnCoFe}-\mathrm{Ac}$. 

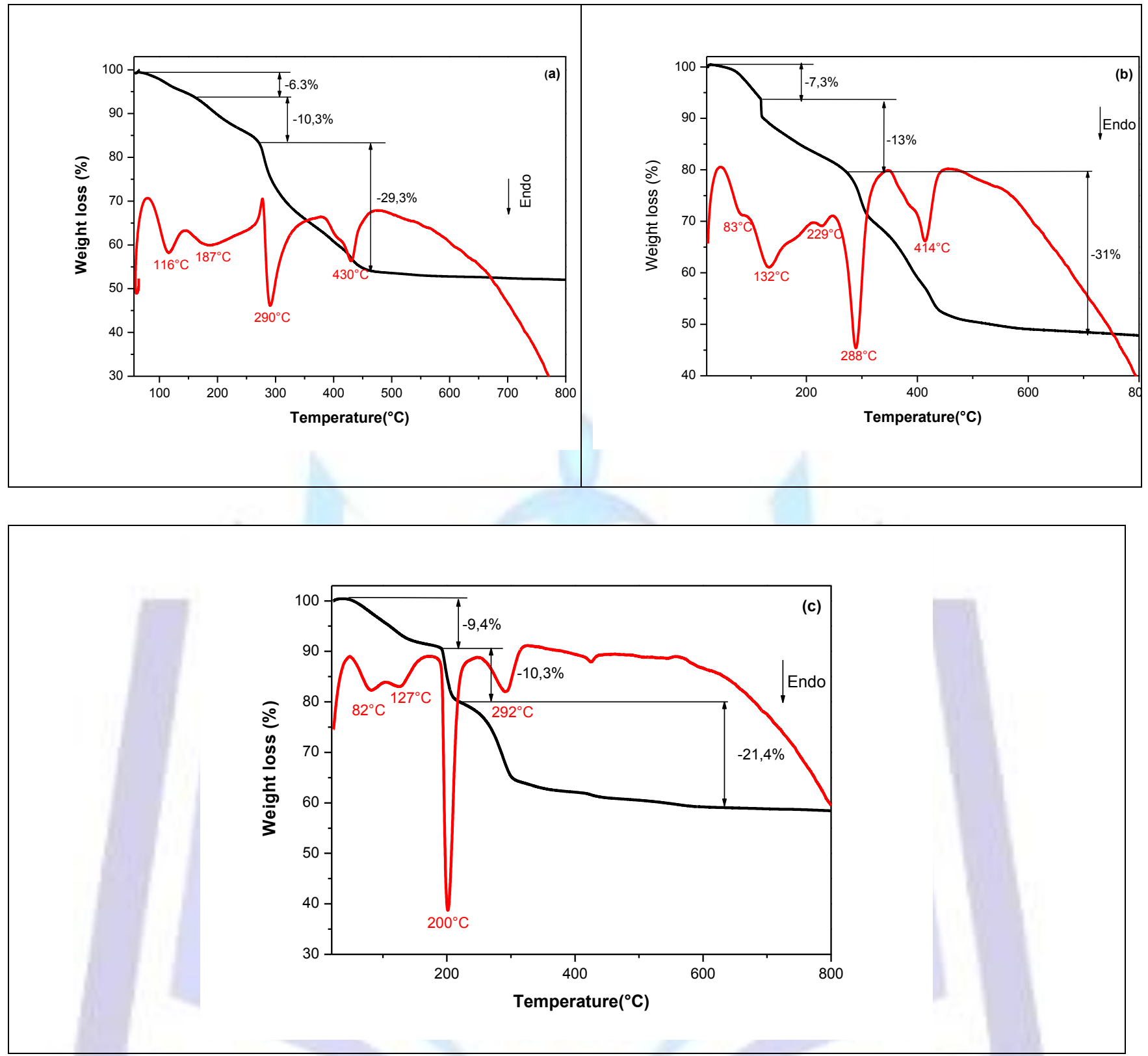

Figure 6: TG/DTA curves of LDHs (a) CoNiFe-Ac, (b) ZnNiFe-Ac, (c) ZnCoFe-Ac.

\section{5. Chemical analysis}

First it should be noted that under synthesis conditions, $\mathrm{Fe}^{2+}$ was oxidized to $\mathrm{Fe}^{3+}$ as confirmed by Mössbauer analysis (as shown hereafter). This is due to the presence of a sufficient amount of water able to oxidize ferrous ion. In Table 2, are summarized the results of elemental chemical analysis of the compounds and their corresponding formulae. It can be observed that in CoNiFe-Ac compound, the calculated $\mathrm{M}^{\prime \prime} / \mathrm{Fe}^{\mathrm{III}}$ ratio is in a good agreement with the experiment data, but in $\mathrm{ZnNiFe}-\mathrm{Ac}$ and $\mathrm{ZnCoFe}-\mathrm{Ac}$ this ratio is larger than in the starting solution.

For all samples, the results show that the observed carbon amount is higher than that expected in the acetate anions; this is due to the adsorption of polyol (DEG) on the surface of compounds as has been seen in the IR study.

Similar results have been observed for Ni-Co hydroxyacetates prepared in polyol medium [23], where the amount of adsorbed polyol has not been taken into account in the chemical formula. 
Table 2: Elemental chemical analysis data of LDH samples

\begin{tabular}{|c|c|c|c|c|c|c|c|c|c|c|}
\hline \multirow[t]{2}{*}{ Compound } & \multicolumn{6}{|c|}{ Mass fractions (\%) } & \multicolumn{2}{|c|}{ 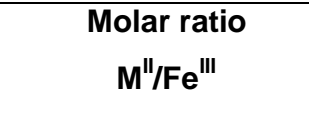 } & \multicolumn{2}{|c|}{$X=M^{\prime \prime \prime} / M^{\prime \prime}+F e^{I I I}$} \\
\hline & Co & $\mathbf{N i}$ & Zn & $\mathrm{Fe}$ & C & $\mathbf{H}$ & solution & solid & solution & solid \\
\hline CoNiFe-Ac & 17.32 & 17.33 & & 10.36 & 6.88 & 3.61 & 3 & 3.17 & 0.25 & 0.24 \\
\hline ZnNiFe-Ac & - & 22.05 & 12.99 & 8.27 & 6.35 & 3.18 & 3 & 3.87 & 0.25 & 0.20 \\
\hline ZnCoFe-Ac & 24.59 & - & 22.46 & 10.1 & 7.79 & 3.61 & 3 & 4.24 & 0.25 & 0.19 \\
\hline \multirow[t]{2}{*}{ Compound } & \multirow{2}{*}{\multicolumn{6}{|c|}{ Chemical formula }} & DEG & $\begin{array}{c}\mathrm{H}_{2} \mathrm{O} \\
\%\end{array}$ & \multicolumn{2}{|c|}{ Total weight loss (\%) } \\
\hline & & & & & & & & Exp & $\operatorname{Exp}$ & Cal \\
\hline CoNiFe-Ac & \multicolumn{6}{|c|}{$\mathrm{Co}_{0.38} \mathrm{Ni}_{0.38} \mathrm{Fe}_{0.24}(\mathrm{OH})_{2} \mathrm{Ac}_{0.24}, 0.52 \mathrm{H}_{2} \mathrm{O}$} & 0.090 & 06.3 & 45.9 & 47.8 \\
\hline ZnNiFe-Ac & \multicolumn{6}{|c|}{$\mathrm{Zn}_{0.28} \mathrm{Ni}_{0.52} \mathrm{Fe}_{0.20}(\mathrm{OH})_{2} \mathrm{Ac} 0.20, \quad 0.70 \mathrm{H}_{2} \mathrm{O}$} & 0.097 & 07.3 & 51.3 & 50.3 \\
\hline ZnCoFe-Ac & \multicolumn{6}{|c|}{$\mathrm{Zn}_{0.37} \mathrm{Co}_{0.44} \mathrm{Fe}_{0.19}(\mathrm{OH})_{2} \mathrm{Ac}_{0.19}, \quad 0.18 \mathrm{H}_{2} \mathrm{O}$} & 0.044 & 09.4 & 41.7 & 41.1 \\
\hline
\end{tabular}

In our study, the amount of adsorbed polyol in the final products has been included in the chemical formula to calculate the theoretical weight losses, which are consistent with those observed by TGA analysis (Table2). Altogether, these results led to the chemical formula $\mathrm{M}^{2+}{ }_{1-\mathrm{x}} \mathrm{Fe}^{3+}{ }_{\mathrm{x}}(\mathrm{OH})_{2}\left(\mathrm{CH}_{3} \mathrm{COO}\right)_{x} \cdot \mathrm{mH}_{2} \mathrm{O} . \mathrm{nDEG}$ (see Table 2 for exact formula).

\section{6. UV-Visible Spectroscopy}

For CoNiFe-Ac and ZnCoFe-Ac, the absorption bands at around 1200 and $500 \mathrm{~nm}$ (Fig. 7(a) and (c)) are attributed to the $\mathrm{d}$-d transitions of octahedral coordinated $\mathrm{Co}^{2+}[24]$. They are assigned as $\mathrm{v}_{1}\left(\mathrm{Co}^{2+}\right):{ }^{4} \mathrm{~T}_{1} \mathrm{~g}(\mathrm{~F}) \stackrel{\mathrm{a}}{\longrightarrow}{ }^{4} \mathrm{~T}_{2 \mathrm{~g}}(\mathrm{~F}), \mathrm{v}_{2}\left(\mathrm{Co}^{2+}\right):$ ${ }^{4} \mathrm{~T} 1 \mathrm{~g}(\mathrm{~F}) \longrightarrow{ }^{4} \mathrm{~A}_{2 \mathrm{~g}}(\mathrm{~F})$, and $\mathrm{v}_{3}\left(\mathrm{Co}^{2+}\right):{ }^{4} \mathrm{~T}_{1 \mathrm{~g}}(\mathrm{~F}) \longrightarrow{ }^{4} \mathrm{~T}_{1 \mathrm{~g}}(\mathrm{P})$ transitions in high spin state $\mathrm{Co}^{2+}\left(\mathrm{d}^{7}\right)$ respectively $[23,25,26]$. The UV-Visible spectra of the CoNiFe-Ac and ZnNiFe-Ac (Fig. 7(a) and (b)) show that $\mathrm{Ni}^{2+}$ ions are also located in octahedral sites with the presence of absorption bands at around 380,665 and $1115 \mathrm{~nm}$ due to $\mathrm{v}_{2}\left(\mathrm{Ni}^{2+}\right)$ :

${ }^{3} \mathrm{~A}_{2} \mathrm{~g}(\mathrm{~F}) \longrightarrow{ }^{3} \mathrm{~T}_{1 \mathrm{~g}}(\mathrm{~F}), \mathrm{v}_{3}\left(\mathrm{Ni}^{2+}\right): 3 \mathrm{~A}_{2 \mathrm{~g}}(\mathrm{~F}) \longrightarrow{ }^{3} \mathrm{~T}_{1 \mathrm{~g}}(\mathrm{P})$, and $\mathrm{v}_{1}\left(\mathrm{Ni}^{2+}\right): 3 \mathrm{~A}_{2 \mathrm{~g}}(\mathrm{~F}) \longrightarrow{ }^{3} \mathrm{~T}_{2 \mathrm{~g}}(\mathrm{~F})$ respectively [27-31]

(Table 3).

Table 3: UV-Visible bands attribution of LDH samples

\begin{tabular}{|c|c|c|}
\hline & $\mathrm{Co}^{2+}(\mathrm{Oh})$ & $\mathrm{Ni}^{2+}(\mathrm{Oh})$ \\
\hline Samples & $\begin{array}{ccc}v_{1}\left({ }^{4} \mathrm{~T}_{2 g}(\mathrm{~F})\right), & v_{2}\left({ }^{4} \mathrm{~A}_{2 \mathrm{~g}}(\mathrm{~F})\right), & v_{3}\left({ }^{4} \mathrm{~T}_{1 \mathrm{~g}}(\mathrm{P})\right) \\
/ \mathrm{nm} & / \mathrm{nm} & / \mathrm{nm}\end{array}$ & $\begin{array}{ccc}v_{1}\left({ }^{3} \mathrm{~T}_{2 \mathrm{~g}}(\mathrm{~F})\right), & v_{2}\left({ }^{3} \mathrm{~T}_{1 \mathrm{~g}}(\mathrm{~F})\right), & v_{3}\left({ }^{3} \mathrm{~T}_{1 \mathrm{~g}}(\mathrm{P})\right) \\
/ \mathrm{nm} & / \mathrm{nm} & / \mathrm{nm}\end{array}$ \\
\hline CoNiFe-Ac & 1200 & 1402 \\
\hline ZnNiFe-Ac & 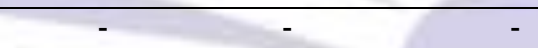 & 665,572 \\
\hline ZnCoFe-Ac & 1220 & - \\
\hline
\end{tabular}




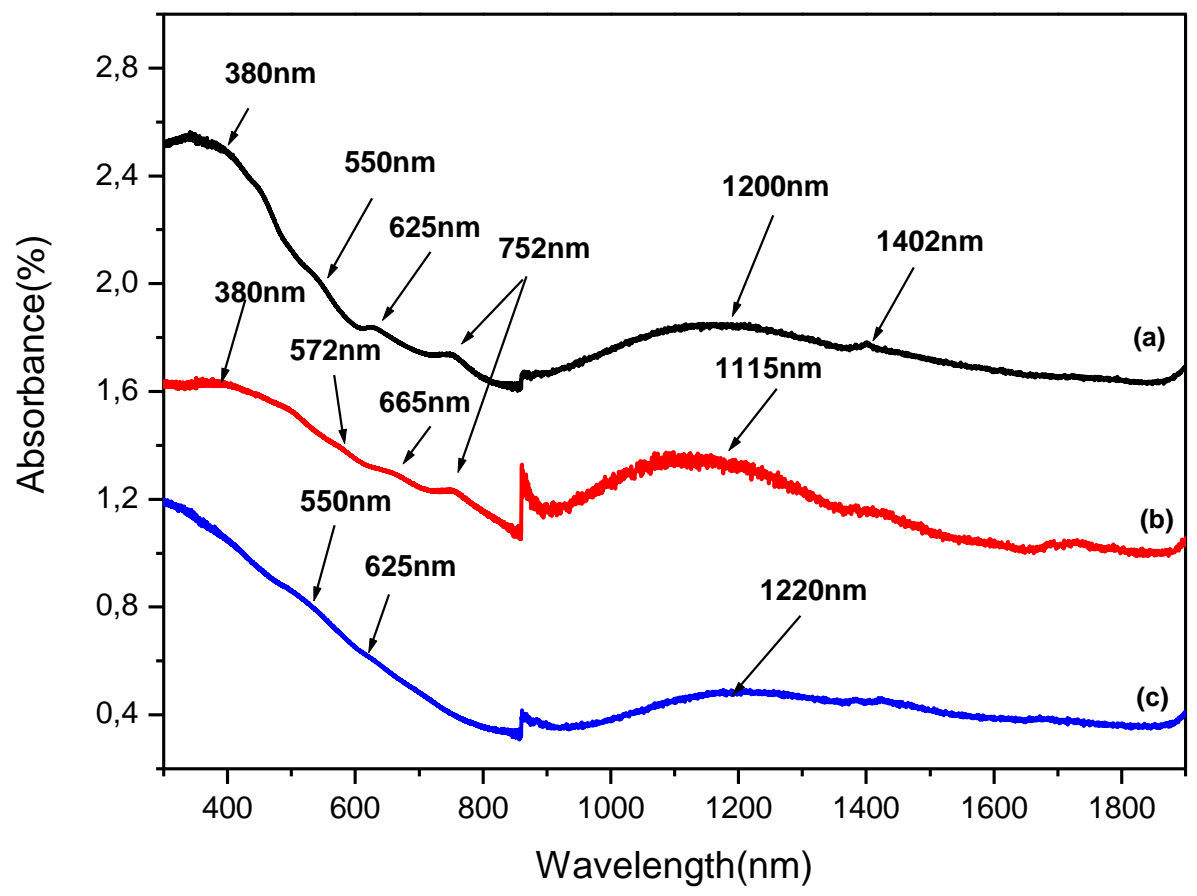

Figure 7: UV-Visible of LDHs (a) CoNiFe-Ac, (b) ZnNiFe-Ac, (c) ZnCoFe-Ac.

\section{7. Mössbauer Spectroscopy}

Fig. 8 shows the Mössbauer spectra for all samples at room temperature in order to probe local magnetic environment around the Fe sites and to determine the oxidation state of the Fe in LDHs matrix.

Each spectrum shows only one doublet with isomer shift $(\delta)$ ranging from 0.33 to $0.34 \mathrm{~mm} / \mathrm{s}$ and quadrupole splitting $(\Delta)$ $0.45-0.56 \mathrm{~mm} / \mathrm{s}$ indicating $\mathrm{Fe}^{3+}$ nature of the $\mathrm{Fe}$ atom, and no evidence of $\mathrm{Fe}^{2+}$ signal was found [32]. The small value of quadrupole splitting $(\Delta)$ corresponds to high spin $\mathrm{Fe}^{3+}$ ions in octahedral site.

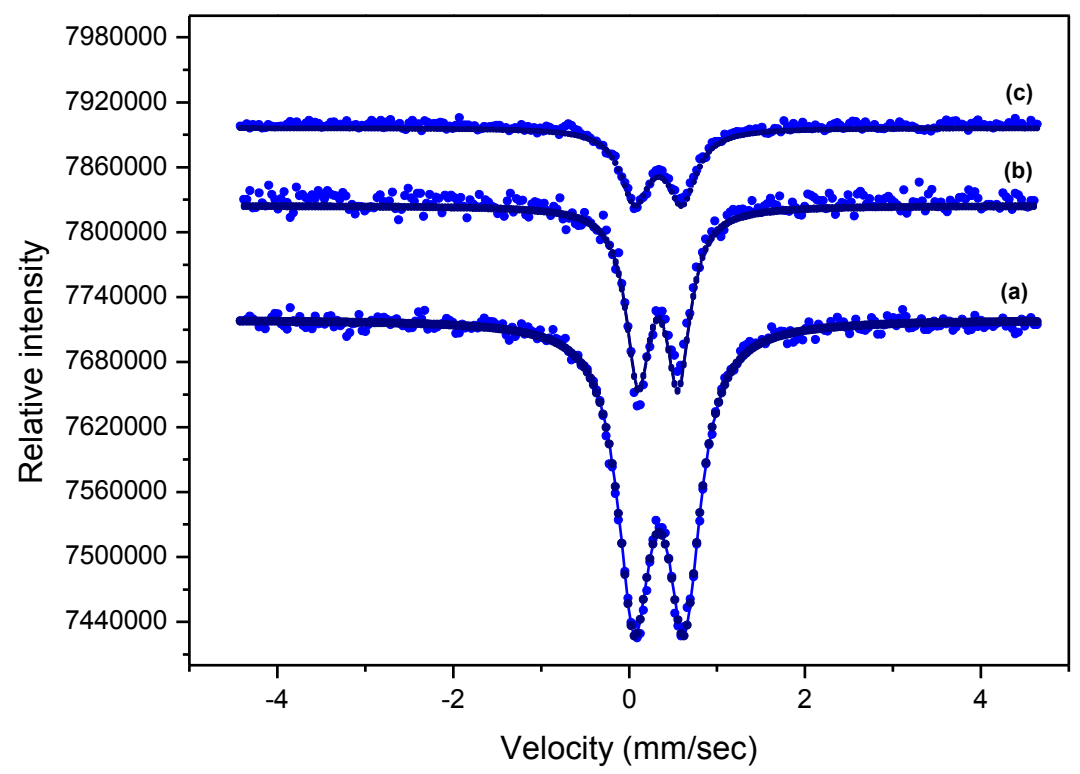

Figure 8: Mössbauer spectra of LDHs (a) CoNiFe-Ac, (b) ZnNiFe-Ac, (c) ZnCoFe-Ac. 


\section{CONCLUSION}

In the current study, a novel series of ternary layered double hydroxides with acetate anion intercalated in the interlayer region has been prepared by forced hydrolysis in polyol medium, in the ratio range $3.17 \leq \mathrm{M}^{\text {II }} \mathrm{Fe}^{\mathrm{III}} \leq 4.24$.

X-Ray diffraction investigations show that these materials derive from the brucite structure with variable basal spacing, the Zinc based compounds having the more higher interlamellar distances.

IR study shows that acetate anions are located in between the brucite sheets as free species. No trace of carbonate $\mathrm{CO}_{3}$ anion was detected.

Because of the turbostratic character of CoNiFe-Ac, ZnNiFe-Ac and ZnCoFe-Ac, it was hard to get more insight into their intralayer structural organization by X-ray diffraction analysis. Thus two complementary analysis techniques namely UVVisible and Mössbauer Spectroscopy have been used.

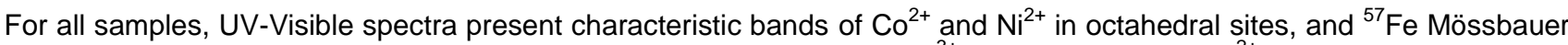
measurement reveals that $\mathrm{Fe}$ atoms are present in the $\mathrm{LDHs}$ lattice in $\mathrm{Fe}^{3+}$ state and no such $\mathrm{Fe}^{2+}$ ions are present.

Owing to their chemical compositions, these based $3 \mathrm{~d}$-transition LDHs are belevied to be very versatile precursors for a wide range of metal-spinel nanocomposites.

\section{ACKNOWLEDGMENTS}

Mossbauer measurements have been conducted at the LPEC - UMR / CNRS 6087 - Université du Maine - Le Mans France. We are grateful to Dr. Jean-Marc Grénèche for this collaboration.

\section{REFERENCES}

[1] Evans, D. G. and Duan, X. 2006. Preparation of layered double hydroxides and their applications as additives in polymers, as precursors to magnetic materials and in biology and medicine. Chem. Commun. 5 (2006) 485 - 496.

[2] Lazaridis, N. K.and Matis, T. A. 2004. Chromium (VI) removal from aqueous solutions by $\mathrm{Mg}-\mathrm{Al}-\mathrm{CO}_{3}$ hydrotalcite: Sorption-desorption kinetic and equilibrium studies. Ind. Eng. Chem. Res. 43 (2004) 2209-2215.

[3] Rives, V. (Ed). 2001. Layered Double Hydroxides: Present and Future, Nova Sci. Pub., Inc., New York, 2001.

[4] Cavani, F., Trifiro, F. and Vaccari, A. 1991. Hydrotalcite-Type Anionic Clays: Preparation, properties and applications. Catalysis Today 11 (1991) 173-301.

[5] Kooli, F., Rives, V. and Ulibarri, M.A. 1995. Preparation And Study Of Decavanadate-Pillared Hydrotalcite-Like Anionic Clays Containing Transition Metal Cations In Layers. 1. Samples Containig Nickel-Aluminum Prepared By Anionic Exchange And Reconstructionlnorg. Chem. 34 (1995) 5114-5121.

[6] Iwasaki,T., Shimizu, K., Nakamura, H. and Watano, S. 2012. Novel mechanochemical process for facile and rapid synthesis of a Co-Fe layered double hydroxide. Mater. Letters 68 (2012) 406-408.

[7] Wu, H., Jiao, Q., Zhao, Y., Huang, S., Li, X., Liu, H., and Zhou, M. 2010. Synthesis of Zn/Co/Fe-layered double hydroxide nanowires with controllable morphology in a water-in-oil microemulsion. Mater. Charact. 61 (2010) $227-232$.

[8] Poul, L., Jouini, N. and Fiévet, F. 2000. Layered hydroxide metal acetates (metal = zinc, cobalt, and nickel): Elaboration via hydrolysis in polyol medium and comparative study. Chem. Mater. 12 (2000) 3123-3132.

[9] Poul, L., Ammar, S., Jouini, N., Fiévet, F. and Villain, F. 2003. Synthesis of inorganic compounds (metal, oxide and hydroxide) in polyol medium: a verstatile route related to the sol-gel process. J. Sol-Gel Sci. Tech. 26 (2003) $261-265$.

[10] Prevot, V., Forano, C. and Besse, J., P. 2005. Hydrolysis in polyol: New route for hybrid-layered double hydroxides preparation. Chem. Mater. 17 (2005) 6695-6701.

[11] Taibi, M., Ammar, S., Schoenstein, F., Jouini, N., Fiévet, F., Chauveau, T. and Grénèche, J-.M. 2008. Powder and film of nickel and iron-layered double hydroxide: Elaboration in polyol medium and characterization J. Phys. Chem. Solids 69 (2008) 1052-1055.

[12] Heredia, A.C,. Oliva, M.I., Agú, U., Zandalazini, C.I., Marchetti, S. G, Herrero, E.R. and Crivello, M.E. 2013. Synthesis, characterization and magnetic behavior of $\mathrm{Mg}-\mathrm{Fe}-\mathrm{Al}$ mixed oxides based on layered double hydroxide. J. Magn. Magn. Mater. 342 ( 2013), 38-46.

[13] Drici-Setti, N., Jouini, N. and Derriche, Z. 2010. Sorption study of an anionic dye - benzopurpurine 4B - on calcined and uncalcined Mg-Al layered double hydroxides J. Phys. Chem. Solids 71 (2010) 556-559.

[14] Triantafyllidis, K. S., Peleka, E. N., Komvokis, V. G. and Mavros, P.P. 2010. J. Colloid Interface Sci. 342 (2010) $427-$ 436.

[15] Guo, Y., Zhang, H., Zhao, L., Li, G. D., Chen, J-S.and Xu, L. 2005. Synthesis and characterization of Cd-Cr and $\mathrm{Zn}-\mathrm{Cd}-\mathrm{Cr}$ layered double hydroxides intercalated with dodecyl sulphate. J. Solid State Chem. 178 (2005) 18301836. 
[16] Venugopal, B.R., Shivakumara, C.and Rajamathi, M. 2007. A composite of layered double hydroxides obtained through random costacking of layers from $\mathrm{Mg}-\mathrm{Al}$ and $\mathrm{Co}-\mathrm{Al} \mathrm{LDHs}$ by delamination-restacking: Thermal decomposition and reconstruction behaviour. Solid State Sci. 9 (2007) 287-294.

[17] Benito, P., Guinea, I., Labajos, F.M.and Rives, V. 2008. Microwave-assisted reconstruction of Ni,Al hydrotalcite-like compound. J. Solid State Chem. 181 (2008) 987-996

[18] Masciocchi, N., Corradi, E., Sironi, A., Moretti, G., Minelli, G.and Porta, P.1997. Preparation, Characterization, andab initioX-Ray Powder Diffraction Study of $\mathrm{Cu}_{2}(\mathrm{OH})_{3}\left(\mathrm{CH}_{3} \mathrm{COO}\right) \cdot \mathrm{H}_{2} \mathrm{O}$. J. Solid State Chem. 131 (1997) 252-262.

[19] Choy, J-H., Kwon, Y-M., Han, K-S, Song, S-W. and Chang, S-H. 1998. Intra- and inter-layer structures of layered hydroxy double salts, Ni1-xZn2x(OH)(2) $\left(\mathrm{CH}_{3} \mathrm{CO}_{2}\right)(2 x)$ center dot $\mathrm{nH}(2) \mathrm{O}$. Mater. lett. 34 (1998) 356-363.

[20] Nakamoto, K. Infrared and Raman Spectra of Inorganic and Coordination Compounds; 4th Ed; Wiley: New York, 1986.

[21] Del Arco, M., Malet, P., Trujillano, R. and Rives, V. 1999. Synthesis and characterization of hydrotalcites containing $\mathrm{Ni}(\mathrm{II})$ and $\mathrm{Fe}(\mathrm{III})$ and their calcination products. Chem. Mater. 11(1999) 624-633.

[22] Marangoni, R., Bouhent, M., Taviot-Guého, C., Wypych, F. and Leroux, F. 2009. Zn2Al layered double hydroxides intercalated and adsorbed with anionic blue dyes: A physico-chemical characterization. J. Colloid Interface Sci. 333 (2009) 120-127.

[23] Taibi, M., Ammar, S., Jouini, N. and Fiévet, F. 2006. Layered nickel-cobalt hydroxyacetates and hydroxycarbonates: Chimie douce synthesis and structural features. J. Phys. Chem. Solids 67 (2006) 932-937.

[24] Porta, P. and Morpurgo, S. 1995. Cu/Zn/Co/Al/Cr-containing hydrotalcite-type anionic clays. Applied Clay Sci. 10 (1995) 31-44.

[25] Verberckmoes, A. A., Weckhuysen, M. and Schoonheydt, R. A.1998. Spectroscopy and coordination chemistry of cobalt in molecular sieves. Microp. Mesop. Mater. 22 (1998) 165- 178.

[26] Lever, A. B. P. "Inorganic Electronic Spectroscopy"; Elsevier: Amsterdam, 1984.

[27] Davidson, A., Tempere, J. F., Che, M., Roulet, H. and Dufour, G. 1996. Spectroscopic studies of nickel(II) and nickel(III) species generated upon thermal treatments of nickel ceria-supported materials. J. Phys. Chem.100 (1996) 4919-4929.

[28] Rives, V. and Kannan, S. 2000. Layered double hydroxides with the hydrotalcite-type structure containing $\mathrm{Cu}^{2+}, \mathrm{Ni}^{2+}$ and $\mathrm{A}^{3+}$. J. Mater. Chem, 10 (2000) 489-495.

[29] Delorme, F., Seron, A., Licheron, M., Veron, E., Giovannelli, F., Beny, C., Jean-Prost, V. and Martineau, D. 2009. Synthesis and anion exchange properties of a $\mathrm{Zn} / \mathrm{Ni}$ double hydroxide salt with a guarinoite structure. J. Solid State Chem. 182 (2009) 2350-2356.

[30] Faure, C., Delmas, C., Fouassier, M. and Willmann, P. 1991. Characterization of a turbostratic Alpha-nickel Hydroxide quantatively obtained from an $\mathrm{NiSO}_{4}$ solution. J. Power Sources 35 (1991) 249-261.

[31] Ludi, A. and Feitknecht, W. 1963. Lichtabsorption und struktur von kristallverbindungen der ubergangsmetalle .1. lichtabsorption und stuktur der hydroxide, halogenide und hydroxidhalogenide von kobalt und nickel. Hel. Chim. Acta 46 (1963) 2226-2238.

[32] Génin, J-.M. R., Aïssa, R., Géhin, A., Abdelmoula, M., Benali, O., Ernstsen, V., Ona-Nguema, G., Upadhyay, C. and Ruby, C. 2005. Fougerite and Fell-III hydroxycarbonate green rust; ordering drprotonation and/or cation substitution; structure of hydrotalcite-like compounds and mythic ferrosic hydroxide $\mathrm{Fe}(\mathrm{OH})((2+\mathrm{x}))$. Solid State Sci. 7 (2005) 545572.

[33] Koch, C. B. 1998. Structures and properties of anionic clay minerals. Hyperfine Interactions 117 (1998) 131 -157.

[34] Refait, P., Abdelmoula, M., Trolard, F., Génin, J.-M.R., Ehrhardt, J.-J. and Bourrié, G. 2001. Mossbauer and XAS study of a green rust mineral; the partial substitution of $\mathrm{Fe}(2+)$ by $\mathrm{Mg}(2+)$. Am. Mineral. 86 (2001) 731-739. 